\title{
Effects of Modified Constrained Induced Movement Therapy to Improve the Upper Limb Functional Activities and Gross Manual Dexterity on Hemiparetic Cerebral Palsy Children
}

Seema, Nagarani Shanmugam and Kannabiran Bhojan*

RVS College of Physiotherapy, Coimbatore, Tamilnadu, India

*Corresponding author: Kannabiran Bhojan, RVS College of Physiotherapy, Coimbatore, Tamilnadu, India, Tel: 91 9487968169; E-mail: physiokanna@gmail.com Rec date: May 25, 2015; Acc date: June 26, 2015; Pub date: July 02, 2015

Copyright: $\odot 2015$ Seema et al. This is an open-access article distributed under the terms of the Creative Commons Attribution License, which permits unrestricted use, distribution, and reproduction in any medium, provided the original author and source are credited.

\section{Abstract}

Background: cerebral palsy is a neuro developmental disorder. It has various types. Hemiparetic cerebral palsy is a type in which the children have limitations in capacity to use the impaired upper limb on daily life activities. This study aims to find out the effects of modified Constraint induced Movement therapy ( modified CIMT) to improve the upper limb functional activities and gross manual dexterity among the children with hemiparetic cerebral palsy.

Methods: 10 children with hemiparetic cerebral palsy were undergone to modified CIMT. Interventions lasted for 4weeks, 4hrs/day, Peadiatric Motor Activity Log(PMAL) to assess the children's upper limb functional activities and box and block to assess gross manual dexterity were used before and after intervention.

Results: The results showed significant improvements on functional measures of PMAL and gross manual dexterity of box and block.

Conclusion: modified CIMT is an effective therapy to improve the upper limb functional activities and gross manual dexterity on the children with hemiparetic cerebral palsy.

Keywords: Cerebral palsy; Modified constraint induced movement therapy; Paediatric motor activity log; Box and block; Gross manual dexterity

\section{Introduction}

Cerebral palsy $(\mathrm{CP})$ is a neuro developmental disorder caused by non-progressive lesion in the immature brain. It may occur before, during or after birth. The early central nervous system damage results in physical disabilities and sensory impairments. The prevalence of $\mathrm{cp}$ is approximately 2- 2.5 per 1000 births, with hemiplegia accounting for approximately $25 \%$ of all new cases worldwide. CP is mainly classified to the spastic, ataxic, dystonic, and choreoathetosis. Hemiplegia is a type of spastic cerebral palsy [1-3].

Impaired hand function is a major debilitating factor for the performance of activities of daily living in hemiplegic cerebral palsy. The impairment of the hand is often the result of damage to the motor cortex and cortico spinal pathways responsible for the fine motor control of the fingers and hand [4]. Recent evidence suggests that children with CP may improve motor performance if provided with sufficient opportunities to practice. One treatment approach that is becoming increasingly popular is constraint-induced movement therapy (CIMT). Constraint Induced Movement therapy is a new technique used in physical rehabilitation to treat individuals with decreased upper extremity functions. It involves constraining the unaffected limb, along with intense therapy, in order to force the use of the affected side with the intent to improve motor function. It is a task driven treatment that combines principles of behavioral psychology and motor learning [5-9].
CIMT is a therapy for children with hemiplegia which involves encouraging use of the affected arm while restricting use of the unaffected arm. The types of restraints have included slings, mitts, splints, and casts. The restraint may be applied from a few hours up to twenty-four hours of a child's day. During the period of constraint the child may receive therapy to facilitate practice using the affected arm from as little as one hour to as much as six hours daily per week. The practice may be formal and structured involving behavioral shaping strategies or be less formal. Modified CIMT is vary in the frequency, duration, and type of constraint in treatment regimen [6-10].

\section{Methods}

\section{Study Design}

An experimental study was conducted to find out the effects of modified CIMT on children with hemiparetic Cerebral Palsy.

\section{Sample}

10 subjects were selected after giving due consideration to inclusion and exclusion criteria.

\section{Sampling method}

Random sampling technique was used to select the samples.

\section{Inclusion Criteria}

- Diagnosis of hemiplegic cerebral palsy 
Citation: Seema, Shanmugam N, Kannabiran Bhojan K (2015) Effects of Modified Constrained Induced Movement Therapy to Improve the Upper Limb Functional Activities and Gross Manual Dexterity on Hemiparetic Cerebral Palsy Children. Int J Neurorehabilitation 2: 1000169. doi: $10.4172 / 2376-0281.1000169$

Page 2 of 3

- Both gender with children aged 8 to 12 years

- Modified Ashworth scale (MAS) grade $>1$ but $<3$

- cognitively competent and able to understand and follow the instructions

- wrist at $20^{\circ}$ flexion and fingers at $10^{\circ}$ flexion

\section{Exclusion Criteria}

- Visual problems

- Prior upper limb surgery

- uncontrollable seizures

- Botulinum toxin A injection in the upper limb within 6 month prior to study

\section{Outcome measures}

Paediatric Motor Activity Log

- How often scale

- How well scale

Box and block

Paediatric Motor Activity Log (PMAL) is the Motor Activity Log scale which is developed for children with unilateral CP and includes a mixture of unimanual and bimanual activities. The child's caregiver was interviewed to evaluate how well and how often the child used their affected upper extremity based on 22 functional activities of young children. The PMAL was scored on a scale from $0-5[4,7,8]$.

Using the Box and Block Test, gross manual dexterity was determined as the maximum number of blocks transported from one compartment of a box to another in $1 \mathrm{~min}$ [11-14].

\section{Procedure}

10 hemi paretic cerebral palsy children were selected. Consent was obtained for the participation of the child and the child's parent prior to enrolment. Pre evaluation was done by Pediatric Motor Activity Log (PMAL) and box and block. Interventions were delivered in children for 4 hours per day for 4 weeks. Post intervention readings were taken after 4 weeks on the same outcome parameters.

The intervention involves restraint of the noninvolved extremity using a sling and engaging the child in uni manual activities with the involved extremity 4 hours a day for 4 weeks. The sling is strapped to the child's trunk. The sling is worn continuously throughout this time period except when a break is requested. The tasks include board games, card games, manipulative games, puzzles, arts and craft, functional task, and gross motor activities. The games like magnetic board for placing the alphabets or shapes, grasping and releasing the objects in various sizes and shapes, transporting the objects, turning and arranging the pictures, tooth picks or clay to create design or objects, place or remove the stickers, tissue paper scrunching-crumble up then throw them, turn a knob, push a button, pour water in a glass etc. Repetitive practice was given in play way method in group setting. As the child improves, the task is made more challenging.

\section{Data analysis and Results}

The aim of the study was to find out the effectiveness of modified Constraint induced movement therapy to improve the upper limb functional activities and gross manual dexterity on children with hemiparetic cerebral palsy.

Table 1 displays the PMAL values for both how well and how often scale of pre and post treatment. The results showed significant differences in improvement on PMAL in both how well (7.85) and how often scale (12.91) which is greater than table value (2.262).so the significant improvement in PMAL score in modified CIMT.

\begin{tabular}{|l|l|l|l|l|l|}
\hline \multicolumn{2}{|l|}{ Variables } & \multicolumn{2}{|l|}{ Mcimt } & $\begin{array}{l}\text { Calculated } \\
\text { value }\end{array}$ & $\begin{array}{l}\text { Table } \\
\text { value }\end{array}$ \\
\hline \multicolumn{2}{|l|}{} & Mean & SD \pm & & \\
\hline \multirow{2}{*}{$\begin{array}{l}\text { PMAL } \\
\text { How well }\end{array}$} & PRE & 1.42 & 0.14 & \multirow{2}{*}{7.85} & \\
\cline { 2 - 6 } & POST & 1.91 & 0.27 & 2.262 \\
\hline $\begin{array}{l}\text { PMAL } \\
\text { How often }\end{array}$ & PRE & 1.39 & 0.28 & \multirow{2}{*}{12.91} & \\
\cline { 2 - 6 } & POST & 3.51 & 0.51 & & \\
\hline
\end{tabular}

Table 1: Comparison between pre and post in PMAL

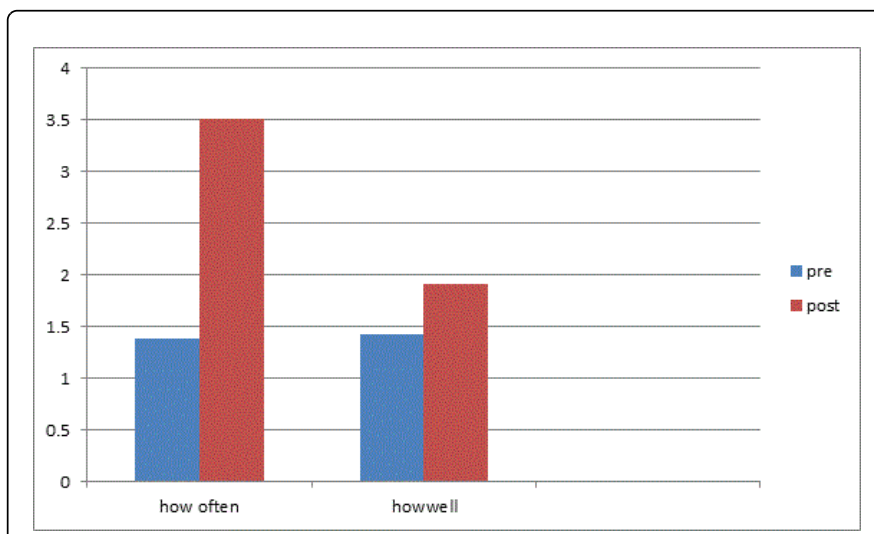

Graph 1: Comparison between pre and post Mean of PMAL

\begin{tabular}{|c|c|c|c|c|c|}
\hline \multicolumn{2}{|l|}{ variables } & \multicolumn{2}{|c|}{ Mcimt } & \multirow[t]{2}{*}{$\begin{array}{l}\text { Calculated } \\
\text { value }\end{array}$} & \multirow{2}{*}{ 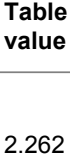 } \\
\hline & & Mean & SD+ & & \\
\hline \multirow{2}{*}{$\begin{array}{l}\text { Box and } \\
\text { Block }\end{array}$} & PRE & 2.3 & 0.94 & 10.85 & \\
\hline & POST & 4.7 & 1.15 & & \\
\hline
\end{tabular}

Table 2: Comparison between pre and post in Box and Block Test

Table 2 displays the box and block values for pre and post treatment of modified CIMT. The result showed significant differences in improvement on box and block (10.85) which is greater than table value (2.262). So the significant improvement in box and block score in modified CIMT. 
Citation: Seema, Shanmugam N, Kannabiran Bhojan K (2015) Effects of Modified Constrained Induced Movement Therapy to Improve the Upper Limb Functional Activities and Gross Manual Dexterity on Hemiparetic Cerebral Palsy Children. Int $\mathrm{J}$ Neurorehabilitation 2: 1000169. doi:10.4172/2376-0281.1000169

Page 3 of 3

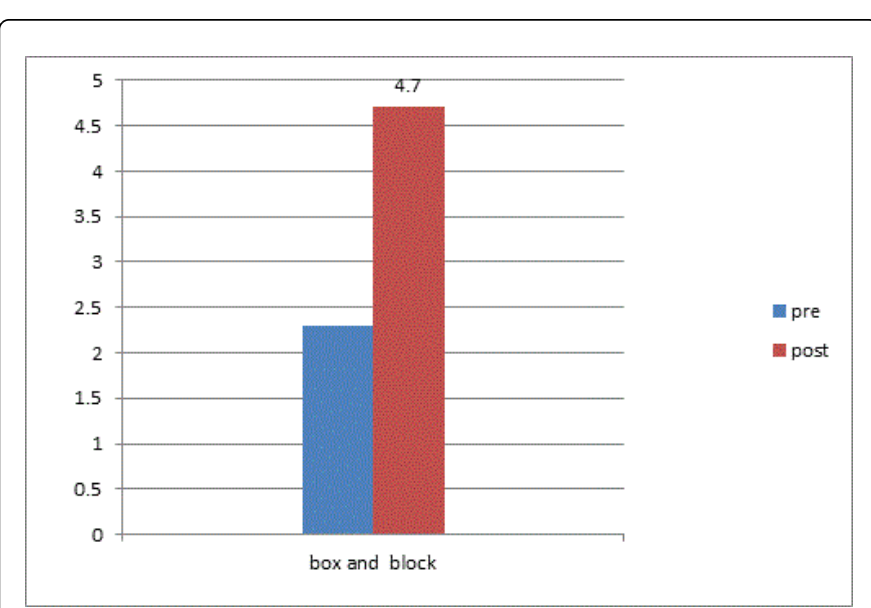

Graph 2: Comparison between pre and post Mean of Box and Blocks

\section{Discussion}

Present study was done to find out the effectiveness of modified CIMT to improve upper limb function activities and gross manual dexterity in children with hemiparetic cerebral palsy.

The modified CIMT had been proven to be effective in improving functional activities and gross manual dexterity of upper limb . The result came in agreement with Eliassion et al. [5] Rostamie et al. [7], Gorden and Charles [8] and Choudhary et al. [9]. Improving functions maybe, using the affected hand more in functional activities and also it has long been believed that the brains of children are felt to have more capability than adults for cortical reorganization and it has been suggested that children with asymmetric upper extremity motor control may also benefit from constraint therapy. Modified CIMT is effective in improving motor recovery in patients with hemiplegia because of increased size and shifting of cortical area neural firing after CIMT $[4,13]$.

\section{Conclusion}

The modified CIMT is a effective treatment method to improve the upper limb functional activities and gross manual dexterity among the children with hemiparetic cerebral palsy.

\section{References}

1. Bialik GM, Givon U (2009) [Cerebral palsy: classification and etiology]. Acta Orthop Traumatol Turc 43: 77-80.

2. Sankar C, Mundkur N (2005) Cerebral palsy-definition, classification, etiology and early diagnosis. Indian J Pediatr 72: 865-868.

3. Jyotsna Gandhi (2007)Cerebral Palsy J Obstet Gynecol 57: 27-36.

4. Sutcliffe TL, Gaetz WC, Logan WJ, Cheyne DO, Fehlings DL (2007) Cortical reorganization after modified constraint-induced movement therapy in pediatric hemiplegic cerebral palsy. J Child Neurol 22: 1281-1287.

5. Eliasson AC, Krumlinde-sundholm L, Shaw K, Wang C (2005) Effects of constraint-induced movement therapy in young children with hemiplegic cerebral palsy: an adapted model. Dev Med Child Neurol 47: 266-275.

6. Andrew M Gordon, Jeanne Charles PT, MSW Steven L, Wolf (2005) Methods of constraint-induced movement therapy for children with hemiplegic cerebral palsy: Development of a child-friendly intervention for improving upper-extremity function Archieves of physical medicine \& rehabilitation 86:837-844.

7. Rostami HR, Arastoo AA, Nejad SJ, Mahany MK, Malamiri RA, Goharpey S (2012) Effects of modified constraint-induced movement therapy in virtual environment on upper-limb function in children with spastic hemiparetic cerebral palsy: a randomised controlled trial. NeuroRehabilitation.3:357-65.

8. Charles J, Gordon AM (2005) A critical review of constraint-induced movement therapy and forced use in children with hemiplegia. Neural Plast 12: 245-261.

9. Choudhary A, Gulati S, Kabra M, Singh UP, Sankhyan N, et al. (2013) Efficacy of modified constraint induced movement therapy in improving upper limb function in children with hemiplegic cerebral palsy: a randomized controlled trial. Brain Dev 35: 870-876.

10. Arnould C, Bleyenheuft Y, Thonnard JL (2014) Hand functioning in children with cerebral palsy. Front Neurol 5: 48.

11. de Bode S, Fritz SL, Weir-Haynes K, Mathern GW (2009) Constraintinduced movement therapy for individuals after cerebral hemispherectomy: a case series. Phys Ther 89: 361-369.

12. Arnould C, Bleyenheuft Y, Thonnard JL (2014) Hand functioning in children with cerebral palsy. Front Neurol 5: 48.

13. Geerdink Y, Aarts P, Geurts AC (2013) Motor learning curve and longterm effectiveness of modified constraint-induced movement therapy in children with unilateral cerebral palsy: a randomized controlled trial. Res Dev Disabil 34: 923-931.

14. Evidence - based care guideline for pediatric constraint induced movement therapy, December 2014. 